\title{
Carvacrol Targets AXL to Inhibit Cell Proliferation and Migration in Non-small Cell Lung Cancer Cells
}

\author{
CHI YOUNG JUNG ${ }^{1 *}$, SO-YOUNG KIM ${ }^{2 *}$ and CHUHEE LEE ${ }^{3}$ \\ ${ }^{1}$ Department of Internal Medicine, College of Medicine, Catholic University of Daegu, Daegu, Republic of Korea; \\ ${ }^{2}$ Department of Pharmacology, School of Medicine, Dongguk University, Gyeongju, Republic of Korea; \\ ${ }^{3}$ Department of Biochemistry and Molecular Biology, School of Medicine, \\ Yeungnam University, Daegu, Republic of Korea
}

\begin{abstract}
Background/Aim: AXL has been reported to be overexpressed and highly activated in various cancer types. In this study, we demonstrated the effect of carvacrol on cell proliferation and migration in non-small cell lung cancer (NSCLC) cells by impeding the expression and activation of AXL. Materials and Methods: The levels of AXL protein, $m R N A$ and promoter activity were evaluated by western blot, reverse transcription polymerase chain reaction (RT-PCR) and luciferase assay, respectively. AXL-overexpressing cells were established by ectopic expression of AXL cDNA. Cell viability, clonogenicity, and migration were measured in carvacrol-treated NSCLC cells. Results: Carvacrol treatment of NSCLC cells caused down-regulation of AXL expression at the transcriptional level and also inhibited phosphorylation of AXL upon ligand stimulation. Carvacrol suppressed cell proliferation and migration and its inhibitory effect was attenuated in $A X L$ overexpressing NSCLC cells. Conclusion: Our data demonstrate that AXL is a crucial therapeutic target of carvacrol-induced inhibition of NSCLC cell proliferation and migration.
\end{abstract}

Lung cancer is the leading cause of cancer-related death worldwide. Between two types of lung cancer, small cell lung cancer (10-15\%) and non-small cell lung cancer (NSCLC, 85\%), the mortality rate of patients with NSCLC is still high (1) because most patients are diagnosed with advanced-stage disease and develop recurrence even after curative radiotherapy or chemotherapy (2). Recently, specific mutations in the epidermal growth factor receptor $(E G F R)$

\footnotetext{
*These Authors contributed equally to this study.

Correspondence to: ChuHee Lee, Ph.D., Department of Biochemistry \& Molecular Biology, School of Medicine, Yeungnam University, 170 Hyun-Chung Ro, Daegu 42415, Republic of Korea. Tel: +82 536406934, Fax: +82 536238032, e-mail: chlee2@ynu.ac.kr
}

Key Words: AXL, carvacrol, proliferation, migration, NSCLC. gene were identified in some cases of NSCLC (3) and this has become a clinically useful target to improve the progression-free survival of patients with these mutations.

In humans, 58 receptor tyrosine kinases have been identified and are categorized into 20 subfamilies (4). There is a small subfamily containing three members, TYRO3, AXL and MER, which is called the TAM family (5). The structural features of TAM receptor tyrosine kinases are very similar, since all of them have extracellular domains which are two immunoglobin-like and two fibronectin type III domains, and cytoplasmic kinase domain with tyrosine residues $(6,7)$.

AXL was first identified in 1988 and cloned in 1991 from chronic myelogenous leukemia cells (8). In a number of cancer types including leukemia (9), breast (10), colon (11), lung (12), ovarian (13), and prostate cancer (14), AXL has been reported to be overexpressed and its activity was also found to be elevated, The growth arrest-specific 6 (GAS6) protein, a common ligand binding to all three TAM kinases, has highest affinity for AXL $(7,15)$. The engagement of AXL by GAS6 evokes its dimerization, which relays various signals leading to cell proliferation, migration, anti-apoptosis, angiogenesis, epithelial-to-mesenchymal transition, and resistance to chemotherapy $(14,16-19)$.

Several studies reported that RNA interference and monoclonal antibodies specific to AXL inhibited its expression and activation, which attenuated xenograft growth of NSCLC and breast cancer $(20,21)$. In metastatic breast cancer models, inhibition of AXL by a selective small molecule inhibitor such as R428 was found to retard tumor spread and extend survival (22). Therefore, restraint of AXL expression and AXL-dependent signaling seems to be a feasible approach to controlling cancer.

Carvacrol (5-isopropyl-2-methylphenol) is a monoterpenoic compound present in essential oils extracted from various aromatic plants such as oregano and thyme. It has been used as food flavoring ingredient and preservative, as well as a fragrance in cosmetic formulations. In addition, carvacrol has been elucidated to have some biological properties including 
antimicrobial, antitumor, and anti-inflammatory activities (23, 24). However, the potential of carvacrol as an anticancer agent and the underlying mechanisms have not yet fully been investigated.

In this study, we examined the effect of carvacrol on the expression and activation of AXL in NSCLC cells in relation to cell proliferation and migration.

\section{Materials and Methods}

Reagents and antibodies. Carvacrol was obtained from Sigma-Aldrich (St. Louis, MO, USA). A549 and H460 cells were purchased from the American Type Culture Collection (Manassas, VA, USA). Primers for $A X L$ and glyceraldehyde-3-phosphate dehydrogenase (GAPDH) were synthesized by Bioneer Corp. (Daejeon, Korea). TRI reagent was obtained from Solgent Co., Ltd. (Daejeon, Korea). AmpliTaq DNA polymerase and Lipofectamine 2000 were obtained from Roche Diagnostics Corp. (Indianapolis, IN, USA) and Invitrogen (Carlsbad, CA, USA), respectively Geneticin, (G418), a selective agent for $A X L$ overexpressing cells was from Gibco BRL (Gaithersburg, MD, USA). The plasmid, pGL3 basic vector, and the Dual-Glo luciferase assay kit were purchased from Promega Corp. (Madison, WI, USA). For western blot analysis, specific antibodies against AXL and GAPDH, as well as secondary antibodies, were obtained from Santa Cruz Biotechnology (Dallas, TX, USA).

Cell culture. The A549 and H460 cells were grown in RPMI 1640 (Gibco BRL) containing 10\% fetal bovine serum (FBS), $2 \mathrm{mM}$ L-glutamine, $10 \mathrm{U} / \mathrm{ml}$ penicillin and $10 \mathrm{~g} / \mathrm{ml}$ streptomycin at $37^{\circ} \mathrm{C}$ in $5 \% \mathrm{CO}_{2}$ in a water-saturated atmosphere.

Reverse transcription polymerase chain reaction (RT-PCR). Cells $\left(2 \times 10^{5}\right)$ were seeded in a $60 \mathrm{~mm}$ culture dish and grown overnight. They were then treated with $0,30,100$ and $300 \mu \mathrm{M}$ of carvacrol for $24 \mathrm{~h}$. Total RNA was then extracted using TRI reagent and subjected to cDNA synthesis and PCR. The specific primers were as follows: AXL sense, 5'-AACCTTCAACTCC TGCCTTCTCG-3' and antisense, 5'-CAGCTTCTCCTTCAGC TCTTCAC-3'; GAPDH sense, 5'-GGAGCCAAAAGGGTCAT CAT-3' and antisense, 5'GTGATGGCATGGACTGTGGT-3'. The mRNA level of AXL was normalized to that of GAPDH.

Promoter activity test. The promoter reporter plasmid, pGL3-AXL, which contains the $A X L$ promoter region ranging from -887 to +7 bp of the transcriptional start site was amplified by PCR and subcloned into the pGL3-basic vector, the luciferase reporter plasmid. The constructed promoter reporter plasmid was cotransfected into cells $\left(3 \times 10^{5}\right.$ cells in a $60-\mathrm{mm}$ dish) with renilla luciferase vectors, pRL-SV40, as an internal control. Luciferase activity was measured using a Dual-Glo luciferase assay system.

Western blot analysis. A549, $\mathrm{H} 460$ or AXL-overexpressing A549 cells were treated with $0,30,100$ and $300 \mu \mathrm{M}$ of carvacrol for $24 \mathrm{~h}$. In addition, $\mathrm{H} 460$ cells were also exposed to $200 \mu \mathrm{M}$ carvacrol for 6,12 and $24 \mathrm{~h}$. To observe the effect of carvacrol on AXL phosphorylation upon GAS6 treatment, serum-starved $\mathrm{H} 460$ cells were treated with $300 \mu \mathrm{M}$ carvacrol for $2 \mathrm{~h}$ and then stimulated with GAS6 for $15 \mathrm{~min}$. After treatment, cells were harvested to prepare total cell lysates using lysis buffer [1\% Triton X-100, $50 \mathrm{mM}$ Tris (pH 8.0), $150 \mathrm{mM} \mathrm{NaCl}$,
$1 \mathrm{mM}$ phenylmethylsulfonyl fluoride, $1 \mathrm{mM} \mathrm{Na}_{3} \mathrm{VO}_{4}$, and protease inhibitor cocktail]. Untreated cells were used as controls. Protein concentrations were determined using Bio-Rad protein assays. Proteins from the cell lysates ( 20 to $40 \mu \mathrm{g}$ ) were separated by $12 \%$ sodium dodecyl sulfate polyacrylamide gel electrophoresis, and electrotransferred onto nitrocellulose membranes. The membranes were blocked for $30 \mathrm{~min}$ at room temperature in Tris-buffered saline with $0.05 \%$ Tween-20 (TTBS) containing 5\% non-fat dry milk, and then incubated with TTBS containing primary antibody for $4 \mathrm{~h}$ at room temperature. After $3 \times 10 \mathrm{~min}$ washes in TTBS, the membranes were incubated with peroxidase conjugated secondary antibody for 1 h. Following three additional 10-min washes with TTBS, the protein bands of interest were visualized using an enhanced chemiluminescence detection system (Amersham ${ }^{\mathrm{TM}}$ ECL $^{\mathrm{TM}}$ Prime Western Blotting Detection Reagent; GE Healthcare, Piscataway, NJ, USA).

Cell viability measurement. To assess cell viability, the number of viable cells was counted using Trypan blue. Briefly, $3 \times 10^{3}$ cells were seeded into $60-\mathrm{mm}$ culture dish, grown overnight and then treated with $0,30,100$ and $300 \mu \mathrm{M}$ of carvacrol for $24 \mathrm{~h}$. After carvacrol treatment, cells were harvested and stained with $0.4 \%$ Trypan blue solution. Dye-excluding viable cells were counted under the microscope. Cell viability was also expressed as a percentage of the viable cells with respect to untreated control cells.

Colony formation assay. A549 and $\mathrm{H} 460$ cells were seeded into 24-well plates $\left(1 \times 10^{2}\right.$ cells/well) and treated with $0,30,100$ and $300 \mu \mathrm{M}$ of carvacrol and then cultured for the next 7 to 10 days to form colonies. Colonies of $>50$ cells were stained with crystal violet (in 60\% methanol; Junsei Chemical Co., Ltd., Tokyo, Japan) and images were acquired using the RAS-3000 Image Analysis System (FujiFilm, Tokyo, Japan).

Overexpression of $A X L$. To ectopically express $A X L$, the recombinant plasmid, pcDNA3-AXL, was constructed by cloning the AXL cDNA into the EcoRI and BamHI sites of the pcDNA3 vector and $2 \mu \mathrm{g}$ of purified plasmids were transfected into the A549 cells $\left(3 \times 10^{5}\right.$ cells in a $100 \mathrm{~mm}$ dish) using Lipofectamine 2000 (Invitrogen, Waltham, MA, USA). To establish stable cell lines, which constitutively express AXL, the transfected cells were cultured in the presence of $400 \mu \mathrm{g} / \mathrm{ml}$ of G418. The RPMI-1640 medium containing G418 was refreshed every 3 days. After 3 to 4 weeks, the $A X L$-expressing cells were enriched and the $A X L$ expression in these cells was analyzed by western blot analysis.

In vitro migration assay. Cells $\left(4 \times 10^{4}\right.$ cells/well $)$ were seeded into collagen I-coated 96-well plates (Essen BioScience, Ann Arbor, MI, USA) and grown overnight to form a monolayer. To rule out cytotoxic effects of carvacrol, cells were treated with $10 \mu \mathrm{g} / \mathrm{ml}$ of mitomycin C for $2 \mathrm{~h}$ prior to the wound-healing assay. According to the manufacturer's instructions, a scratch wound was made in the monolayer and the detached cells were removed by washing with PBS. Cells were then incubated with $0,30,100$ and $300 \mu \mathrm{M}$ of carvacrol for the next $24 \mathrm{~h}$ and the wound width was measured every $4 \mathrm{~h}$ using IncuCyte software (Essen BioScience, Ann Arbor, MI, USA).

Statistical analysis. Data are expressed as the means \pm SD of triplicate samples or at least three independent experiments. To determine statistical significance, Student's $t$-test was used with a $p$-value less than 0.05 indicating significance. 


\section{Results}

Carvacrol inhibits AXL expression at the transcriptional level. We first examined the effect of carvacrol on AXL protein level in NSCLC cells. As shown in Figure 1A, AXL protein level in carvacrol-treated cells was reduced in a dosedependent manner. We also found that carvacrol treatment of cells caused time-dependent inhibition of AXL protein expression (Figure 1B).

The effect of carvacrol on AXL expression was further investigated by reverse transcription polymerase chain reaction. The $A X L$ mRNA level in A549 and H460 cells was found to dose-dependently decrease with carvacrol treatment (Figure 1C), which is consistent with Western blot results. Next, the promoter activity of the $A X L$ gene was also measured using cells containing the $A X L$ promoter-luciferase reporter plasmid, pGL3-AXL. As shown in Figure 1D, carvacrol treatment of cells resulted in dose-dependent decline of $A X L$ promoter activity. These data suggest that carvacrol suppresses AXL expression at the transcriptional level.

Carvacrol blocks activation of AXL in response to ligand stimulation. Engagement of AXL by ligands such as GAS6 causes its dimerization and the subsequent phosphorylation of tyrosine residues located in the cytosolic kinase domain (7). We also found and previously reported GAS6-induced phosphorylation of AXL in NSCLC cells (25). As shown in Figure 1E, pre-incubation of cells with carvacrol profoundly inhibited GAS6-induced phosphorylation of AXL, indicating the inhibitory effect of carvacrol on AXL activation in response to GAS6 stimulation.

Carvacrol reduces cell proliferation and its antiproliferative effect is correlated with AXL protein level. AXL has been reported to transduce diverse extracellular signals to cause cell survival, proliferation and inhibition of apoptosis (14, 16, 26-28). We asked if carvacrol alters cell viability, which is related to its inhibitory effect on AXL expression. A549 and H460 cells were incubated with carvacrol, and the number of viable cells was then counted. We found that carvacrol reduced cell viability in a dose-dependent manner (Figure 2A). Of note, treatment of A549 and H460 cells with $300 \mu \mathrm{M}$ carvacrol resulted in only $34.3 \%$ and $40.8 \%$ cell survival, respectively.

To confirm the antiproliferative effect of carvacrol, clonogenic assay was also performed. As shown in Figure $2 \mathrm{~B}$, colony formation was suppressed by carvacrol treatment. In particular, both A549 and $\mathrm{H} 460$ cells failed to form colonies at carvacrol concentrations higher than $100 \mu \mathrm{M}$.

Next, we examined if the reduction of cell viability by carvacrol is related to its inhibitory effect on AXL expression. To do this, $A X L$-overexpressing A549 cells, A549/pcDNA3AXL, were established and exposed to the same concentrations of carvacrol. Western blot showed that AXL protein was greater in A549/pcDNA3-AXL cells compared to the control cells transfected with empty vector, A549/pcDNA3, (Figure 2C). The cell viability of A549/pcDNA3-AXL cells was found to be higher than that of the control cells after carvacrol treatment (Figure 2D). Colony-formation assay also showed that A549/pcDNA3-AXL cells formed more colonies than the control cells (Figure 2E), indicating that AXL overexpression attenuated the antiproliferative effects of carvacrol. Taken together, these results demonstrated that carvacrol downregulates AXL expression, which results in the inhibition of cell proliferation.

The inhibitory effect of carvacrol on cell migration is attenuated by overexpression of AXL. Since AXL-mediated signaling pathways modulate cell migration and invasion (2931 ), we examined the effect of carvacrol on cell migration via wound-healing assays. Both control cells, A549/pcDNA3, and AXL-overexpressing cells, A549/pcDNA3-AXL, migrated into the wound and closed it within $24 \mathrm{~h}$ (data not shown). As demonstrated in Figure 3A, carvacrol inhibited cell migration in a dose-dependent manner, which was independent of proliferation. When the wound width was expressed as a percentage relative to the original size, exposure of cells to $300 \mu \mathrm{M}$ carvacrol for $24 \mathrm{~h}$ resulted in only $22.3 \%$ (A549/pcDNA3) and 59.3\% (A549/pcDNA3AXL) reduction of wound width, respectively (Figure $3 \mathrm{~B}$ ). Notably, compared to the control cells, accelerated wound healing was found in A549/pcDNA3-AXL cells with elevated AXL protein level, indicating that the effect of carvacrol on cell migration is correlated to AXL protein level, which is also consistent with the results from the cell viability as well as colony formation assay.

\section{Discussion}

Extensive research has been focused on various herbs, fruits, vegetables, spices, and plants to explore the biologically active natural dietary compounds which could be developed as therapeutic products. Carvacrol has been shown to be cytotoxic against many bacteria, yeast and fungi, which is mediated by destruction of the membrane of pathogens and increase of the membrane permeability (32). In mammalian cells, transient receptor potential melastatin-like 7 channel (TRPM7) which is permeable to divalent cations such as $\mathrm{Ca}^{2+}$ and $\mathrm{Mg}^{2+}$ had been reported to be inactivated by carvacrol (33). Luo et al. demonstrated that carvacrol caused significant reduction of TRPM7-like current which increases intracellular $\mathrm{Ca}^{2+}$ concentrations to inhibit cell proliferation and migration of prostate cancer cells, indicating that TRPM7 is a useful target of carvacrol to control pathogenesis of prostate cancer (33). The inhibitory effects of carvacrol on TRPM7 and TRPM7-like currents were also 
A

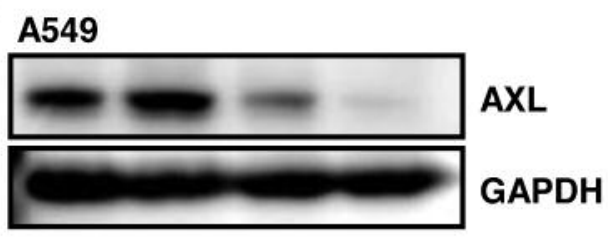

H460

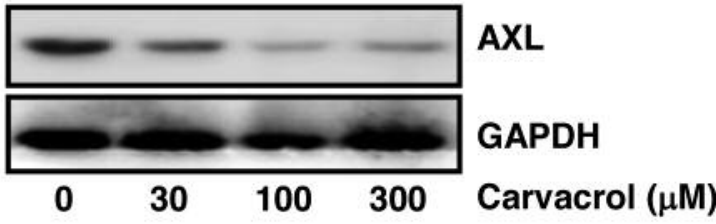

B

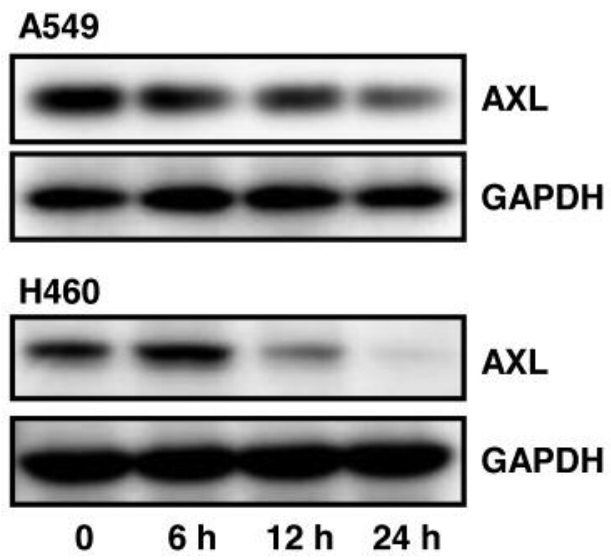

C A549

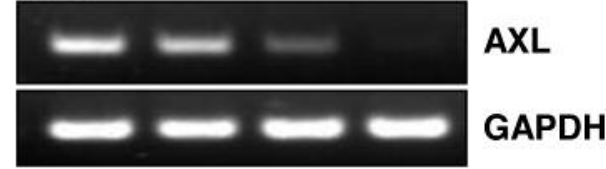

H460

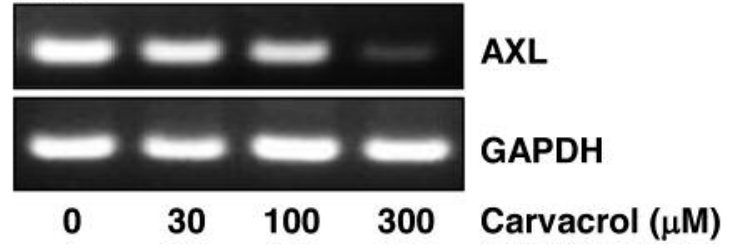

D

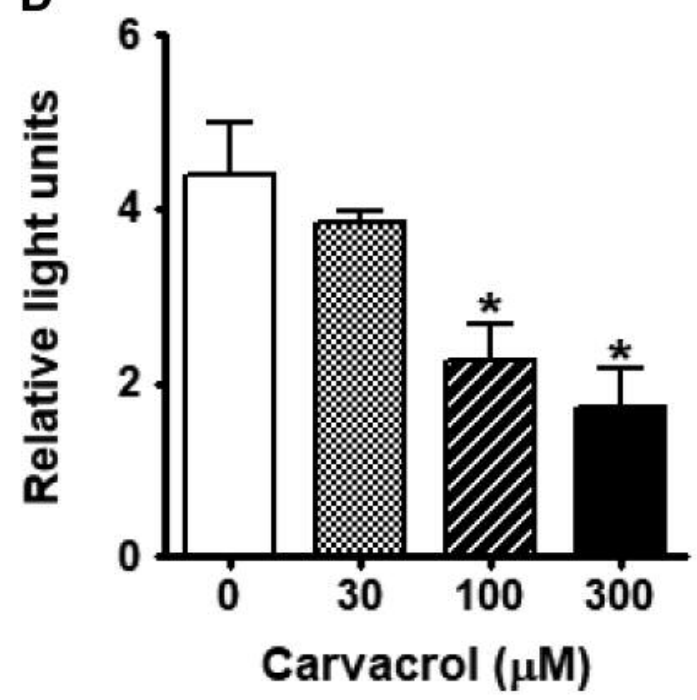

E

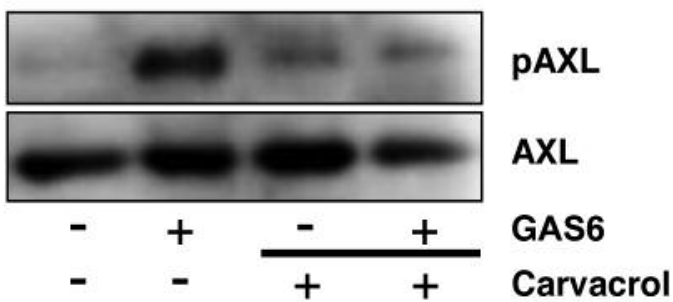

Figure 1. Carvacrol inhibits AXL expression at transcriptional level and activation upon growth arrest-specific 6 (GAS6) stimulation. A549 and H460 cells $\left(5 \times 10^{5}\right.$ cells $)$ were seeded onto 60-mm dishes, grown overnight and exposed to carvacrol at 30, 100, and $300 \mu \mathrm{M}$ carvacrol for $24 \mathrm{~h}(\mathrm{~A})$ or with $300 \mu \mathrm{M}$ carvacrol for 6, 12 and $24 \mathrm{~h}(B)$. AXL protein levels were then determined by western blot analysis. Glyceraldehyde-3-phosphate dehydrogenase $(G A P D H)$ was used as a loading control. Results shown are representative of three independent experiments. $C$ : For reverse transcription-polymerase chain reaction (RT-PCR), total RNA from A549 and $H 460$ cells were treated with the indicated concentrations of carvacrol for 24 h, then isolated and used to determine AXL mRNA levels. As an internal control, GAPDH mRNA was also amplified by RT-PCR. The data shown are representative of three independent experiments. D: To test the effect of carvacrol on AXL promoter activity, H460 cells $\left(5 \times 10^{5}\right.$ cells) were transfected with pGL3 or pGL3AXL using Lipofectamine 2000. The cells were then incubated with the indicated concentrations of carvacrol for $6 \mathrm{~h}$ and total cell lysates were used to measure luciferase activity. Data are expressed as the means $\pm S D$ of triplicate samples conducted in three independent experiments. *Significantly different compared to the control value ( $p<0.05 \mathrm{vs}$. untreated group). E: H460 cells were seeded onto 60-mm dishes. After serum-starvation overnight, cells were pre-incubated with $300 \mu \mathrm{M}$ carvacrol for $2 \mathrm{~h}$ and treated with $250 \mathrm{ng} / \mathrm{ml}$ GAS6 for $15 \mathrm{~min}$. The level of phosphorylated AXL protein was determined by western blot analysis. Total AXL protein level was used as a loading control. Result shown is representative of three independent experiments. 


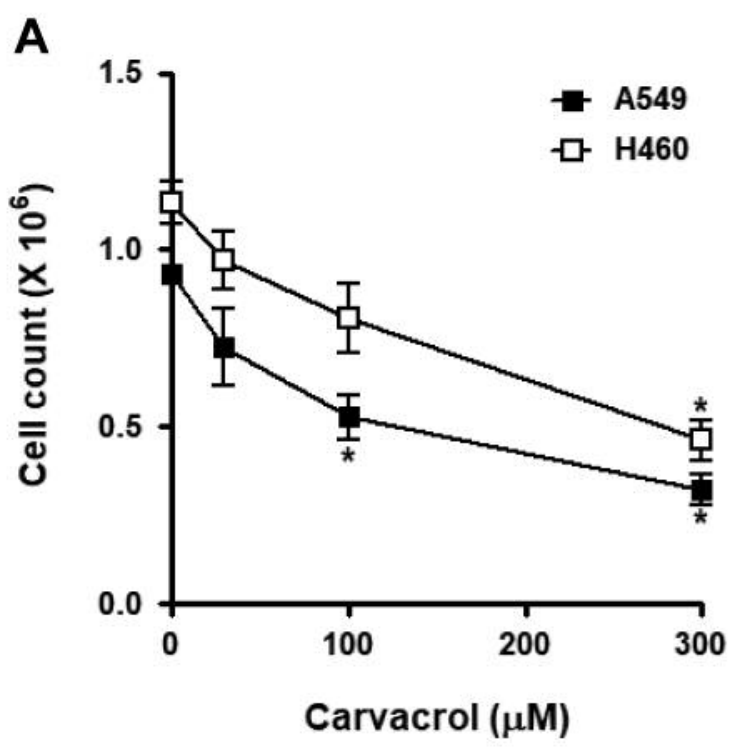

B
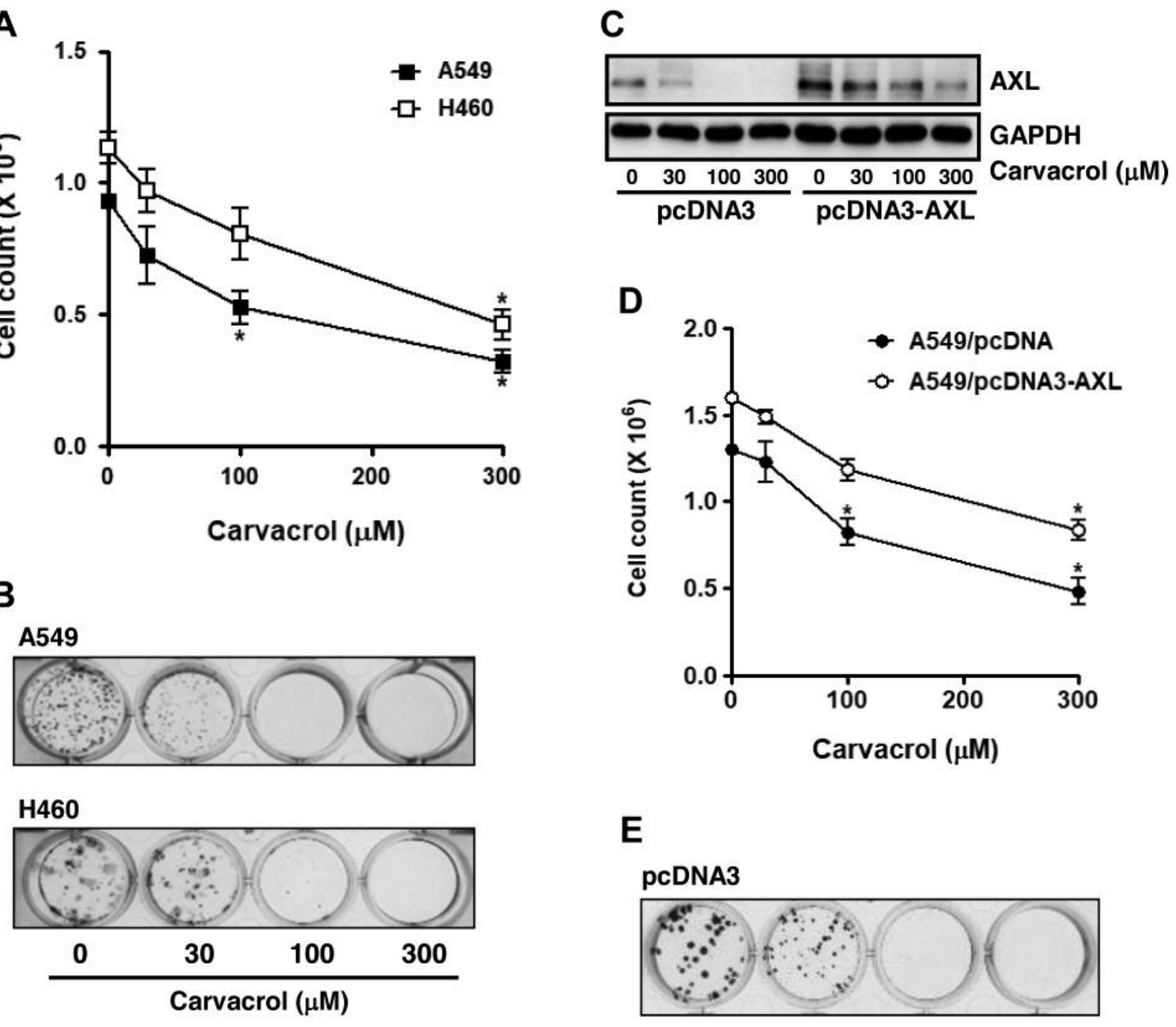

E
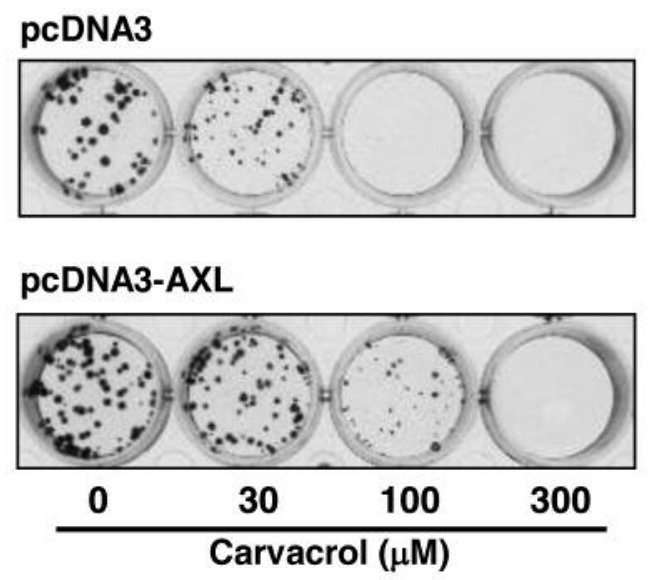

Figure 2. Carvacrol suppresses cell proliferation and its antiproliferative effect is attenuated by overexpression of AXL protein. A: A549 and H460 cells $\left(5 \times 10^{5}\right.$ cells) were seeded onto $60 \mathrm{~mm}$ dishes and grown overnight. Cells were treated with 30, 100, and $300 \mu \mathrm{M}$ carvacrol for $24 \mathrm{~h}$. Trypan blue exclusion assay was carried out to count the number of viable cells. Data are presented as the mean $\pm S D$ of at least three independent experiments. The asterisks indicate the significant difference compared to the control value. B: Cells $\left(0.5\right.$ to $1 \times 10^{3}$ cells/well) were seeded onto 24 -well plates, treated with the indicated concentrations of carvacrol and allowed to grow for 7 to 10 days. Crystal violet staining was next conducted to visualize the colonies formed by cell proliferation. The data shown are representative of three independent experiments. C: A549 cells were transfected with pcDNA3 or pcDNA3-AXL plasmid using Lipofectamine 2000. Both A549/pcDNA3 and A549/pcDNA3-AXL cells were treated with the indicated concentrations of carvacrol for $24 \mathrm{~h}$. AXL protein level was determined by western blot analysis. Glyceraldehyde-3-phosphate dehydrogenase $(G A P D H)$ was used as a loading control. Result shown is representative of three independent experiments. D: Cells were treated with the indicated doses of carvacrol for $24 \mathrm{~h}$ and stained with trypan blue and the viable cells were then counted. Data are expressed as the means $\pm S D$ from three independent experiments. E: Colony formation assay was conducted using A549/pcDNA3 and A549/pcDNA3-AXL cells. Cells were exposed to the indicated concentrations of carvacrol and allowed to grow for 7 to 10 days. Crystal violet staining was carried out to visualize the colonies formed by proliferating cells. The data shown are representative of three independent experiments. *Significantly different at $p<0.05 v s$. untreated group. 
confirmed in HEK293 and glioblastoma cells (34). However, therapeutic targets of carvacrol and the underlying mechanisms to explain its biological activities have not yet been fully investigated.

In this study, we observed that carvacrol suppressed the expression of AXL at the transcriptional level (Figure 1A-D). To our knowledge, this is the first report that carvacrol targets AXL and down-regulates its expression. Since AXL has been found to play important roles in cell survival, proliferation, adhesion and migration, we next examined the inhibitory effect of carvacrol on AXL expression in association with its antiproliferative activity. As shown in Figure $2 \mathrm{~A}$ and B, the cell viability and colony formation ability of A549 and H460 NSCLC cells were reduced by carvacrol in a dose-dependent manner. This was consistent with many earlier reports showing the antiproliferative effect of carvacrol in breast cancer (35), colon cancer (36), gastric adenocarcinoma (37), glioblastoma, hepatocellular carcinoma (38), NSCLC (39), oral cancer (40), and prostate cancer (33). Interestingly, the inhibitory effect of carvacrol on cell viability and colony formation was attenuated by ectopic expression of AXL (Figure 2D and E), indicating that carvacrol down-regulates $A X L$ expression to result in the inhibition of cell proliferation.

Moreover, upon engagement of AXL with the ligand GAS6 carvacrol was also found to profoundly inhibit phosphorylation of AXL (Figure 1E), showing that carvacrol has an inhibitory effect on both AXL expression and activation, which might support its potential as an anticancer drug.

The wound-healing assay showed that carvacrol treatment of cells suppressed cell migration, which was somewhat compensated by the elevation of AXL expression (Figure 3A and $\mathrm{B})$. These results are consistent with clinical data in lung cancer tissues showing that disease stage and metastasis were positively associated with the protein level of AXL and ligands, as well as its activation status (13).

In summary, our data indicate that carvacrol has inhibitory effects on AXL expression and its activation in response to GAS6 binding, that are associated with its antiproliferative activity and inhibition of cell migration by NSCLC cells. Thus, AXL is confirmed to be a potent therapeutic target of carvacrol in inhibiting cell proliferation and migration of NSCLC cells.

\section{Acknowledgements}

This work was supported by the 2015 Yeungnam University Research Grant (No. 215A380059).

\section{References}

1 Ettinger DS, Akerley W, Borghaei H, Chang AC, Cheney RT, Chirieac LR, D'Amico TA, Demmy TL, Govindan R, Grannis FW Jr., Grant SC, Horn L, Jahan TM, Komaki R, Kong FM, Kris MG, Krug LM, Lackner RP, Lennes IT, Loo BW Jr., Martins R, Otterson GA, Patel JD, Pinder-Schenck MC, Pisters KM,
A pcDNA3

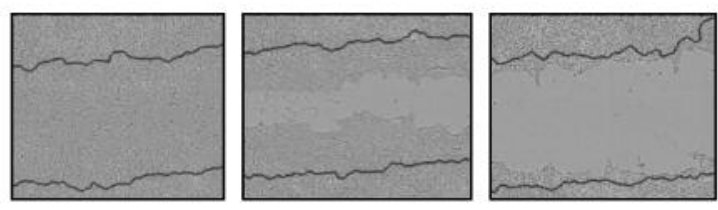

pcDNA3-AXL
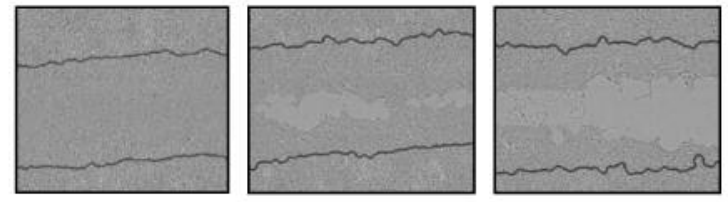

B

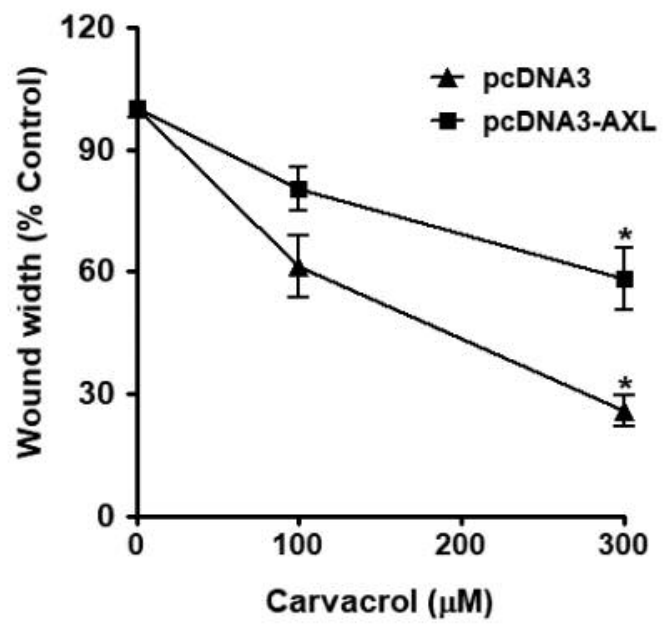

Figure 3. Carvacrol inhibits cell migration, which is inversely proportional to AXL protein levels. A549/pcDNA3 and A549/pcDNA3AXL cells $\left(4 \times 10^{4}\right)$ cells were seeded into 96-well plates, and grown overnight. A scratch wound was made through each monolayer of cells. Cells were then treated with the indicated concentrations of carvacrol for $24 \mathrm{~h}$. The initial wound edges are shown in solid lines. Result shown is a representative of three independent experiments (A). The wound width as a percentage of the initial width was calculated at $24 \mathrm{~h}$ postincubation using IncuCyte software (B). Data are expressed as the mean $\pm S D$ of triplicate samples.

Reckamp K, Riely GJ, Rohren E, Shapiro TA, Swanson SJ, Tauer $\mathrm{K}$, Wood DE, Yang SC, Gregory K, Hughes M and National Comprehensive Cancer Network: Non-small cell lung cancer, version 2.2013. J Natl Compr Canc Netw 11(6): 645-65, 2013.

2 Siegel R, DeSantis C, Virgo K, Stein K, Mariotto A, Smith T, Cooper D, Gansler T, Lerro C, Fedewa S, Lin C, Leach C, Cannady RS, Cho H, Scoppa S, Hachey M, Kirch R, Jemal A and Ward E: Cancer treatment and survivorship statistics, 2012. CA Cancer J Clin 62(4): 220-241, 2012. 
3 Cappuzzo F, Hirsch FR, Rossi E, Bartolini S, Ceresoli GL, Bemis L, Haney J, Witta S, Danenberg K, Domenichini I, Ludovini V, Magrini E, Gregorc V, Doglioni C, Sidoni A, Tonato M, Franklin WA, Crino L, Bunn PA Jr. and Varella-Garcia M: Epidermal growth factor receptor gene and protein and gefitinib sensitivity in nonsmall-cell lung cancer. J Natl Cancer Inst 97(9): 643-655, 2005.

4 Robinson DR, Wu YM and Lin SF: The protein tyrosine kinase family of the human genome. Oncogene 19(49): 5548-5557, 2000 .

5 Lemke G: Biology of the TAM receptors. Cold Spring Harb Perspect Biol 5(11): a009076, 2013.

6 Heiring C, Dahlback B and Muller YA: Ligand recognition and homophilic interactions in TYRO3: structural insights into the AXL/TYRO3 receptor tyrosine kinase family. J Biol Chem 279(8): 6952-6958, 2004.

7 Sasaki T, Knyazev PG, Clout NJ, Cheburkin Y, Gohring W, Ullrich A, Timpl R and Hohenester E: Structural basis for GAS6-AXL signalling. EMBO J 25(1): 80-87, 2006.

8 O'Bryan JP, Frye RA, Cogswell PC, Neubauer A, Kitch B, Prokop C, Espinosa R, 3rd, Le Beau MM, Earp HS and Liu ET: $A X L$, a transforming gene isolated from primary human myeloid leukemia cells, encodes a novel receptor tyrosine kinase. Mol Cell Biol 11(10): 5016-5031, 1991.

9 Rochlitz C, Lohri A, Bacchi M, Schmidt M, Nagel S, Fopp M, Fey MF, Herrmann R and Neubauer A: AXL expression is associated with adverse prognosis and with expression of BCL2 and CD34 in de novo acute myeloid leukemia (AML): results from a multicenter trial of the Swiss Group for Clinical Cancer Research (SAKK). Leukemia 13(9): 1352-1358, 1999.

10 Berclaz G, Altermatt HJ, Rohrbach V, Kieffer I, Dreher E and Andres AC: Estrogen dependent expression of the receptor tyrosine kinase AXL in normal and malignant human breast. Ann Oncol 12(6): 819-824, 2001.

11 Craven RJ, Xu LH, Weiner TM, Fridell YW, Dent GA, Srivastava S, Varnum B, Liu ET and Cance WG: Receptor tyrosine kinases expressed in metastatic colon cancer. Int $\mathrm{J}$ Cancer 60(6): 791-797, 1995.

12 Shieh YS, Lai CY, Kao YR, Shiah SG, Chu YW, Lee HS and Wu $\mathrm{CW}$ : Expression of AXL in lung adenocarcinoma and correlation with tumor progression. Neoplasia 7(12): 1058-1064, 2005.

13 Rankin EB, Fuh KC, Taylor TE, Krieg AJ, Musser M, Yuan J, Wei K, Kuo CJ, Longacre TA and Giaccia AJ: AXL is an essential factor and therapeutic target for metastatic ovarian cancer. Cancer Res 70(19): 7570-7579, 2010.

14 Shiozawa Y, Pedersen EA, Patel LR, Ziegler AM, Havens AM, Jung Y, Wang J, Zalucha S, Loberg RD, Pienta KJ and Taichman RS: GAS6/AXL axis regulates prostate cancer invasion, proliferation and survival in the bone marrow niche. Neoplasia 12(2): 116-127, 2010.

15 Stitt TN, Conn G, Gore M, Lai C, Bruno J, Radziejewski C, Mattsson K, Fisher J, Gies DR, Jones PF, Masiakowski P, Ryan TE, Tobkes NJ, Chen DH, DiStefano PS, Long GL, Basilico C, Goldfarb MP, Greg Lemke G, Glass DJ and Yancopoulos GD: The anticoagulation factor protein $\mathrm{S}$ and its relative, GAS6, are ligands for the anticoagulation factor protein $\mathrm{S}$ and its relative family of receptor tyrosine kinases. Cell 80(4): 661-670, 1995.

16 Goruppi S, Ruaro E and Schneider C: GAS6, the ligand of AXL tyrosine kinase receptor, has mitogenic and survival activities for serum starved NIH3T3 fibroblasts. Oncogene 12(3): 471480,1996
17 Gustafsson A, Martuszewska D, Johansson M, Ekman C, Hafizi S, Ljungberg B and Dahlback B: Differential expression of AXL and GAS6 in renal cell carcinoma reflecting tumor advancement and survival. Clin Cancer Res 15(14): 4742-4749, 2009.

18 Antony J and Huang RY: AXL-driven EMT state as a targetable conduit in cancer. Cancer Res 77(14): 3725-3732, 2017

19 Zhang Z, Lee JC, Lin L, Olivas V, Au V, LaFramboise T, AbdelRahman M, Wang X, Levine AD, Rho JK, Choi YJ, Choi CM, Kim SW, Jang SJ, Park YS, Kim WS, Lee DH, Lee JS, Miller VA, Arcila M, Ladanyi M, Moonsamy P, Sawyers C, Boggon TJ, Ma PC, Costa C, Taron M, Rosell R, Halmos B and Bivona TG: Activation of the AXL kinase causes resistance to EGFRtargeted therapy in lung cancer. Nat Genet 44(8): 852-860, 2012.

$20 \mathrm{Li}$ Y, Ye X, Tan C, Hongo JA, Zha J, Liu J, Kallop D, Ludlam MJ and Pei L: AXL as a potential therapeutic target in cancer: role of AXL in tumor growth, metastasis and angiogenesis. Oncogene 28(39): 3442-3455, 2009.

21 Ye X, Li Y, Stawicki S, Couto S, Eastham-Anderson J, Kallop D, Weimer R, Wu Y and Pei L: An anti-AXL monoclonal antibody attenuates xenograft tumor growth and enhances the effect of multiple anticancer therapies. Oncogene 29(38): 5254-5264, 2010.

22 Holland SJ, Pan A, Franci C, Hu Y, Chang B, Li W, Duan M, Torneros A, Yu J, Heckrodt TJ, Zhang J, Ding P, Apatira A, Chua J, Brandt R, Pine P, Goff D, Singh R, Payan DG and Hitoshi Y: $\mathrm{R} 428$, a selective small molecule inhibitor of AXL kinase, blocks tumor spread and prolongs survival in models of metastatic breast cancer. Cancer Res 70(4): 1544-1554, 2010.

23 Ultee A, Slump RA, Steging G and Smid EJ: Antimicrobial activity of carvacrol toward Bacillus cereus on rice. J Food Prot 63(5): 620-624, 2000

24 Baser KH: Biological and pharmacological activities of carvacrol and carvacrol bearing essential oils. Curr Pharm Des 14(29): 3106-3119, 2008.

$25 \mathrm{Kim} \mathrm{KC}$, Baek SH and Lee C: Curcumin-induced downregulation of AXL receptor tyrosine kinase inhibits cell proliferation and circumvents chemoresistance in non-small lung cancer cells. Int J Oncol 47(6): 2296-2303, 2015.

26 Linger RM, Cohen RA, Cummings CT, Sather S, Migdall-Wilson J, Middleton DH, Lu X, Baron AE, Franklin WA, Merrick DT, Jedlicka P, DeRyckere D, Heasley LE and Graham DK: MER or AXL receptor tyrosine kinase inhibition promotes apoptosis, blocks growth and enhances chemosensitivity of human nonsmall cell lung cancer. Oncogene 32(29): 3420-3431, 2013.

27 Martinelli E, Martini G, Cardone C, Troiani T, Liguori G, Vitagliano D, Napolitano S, Morgillo F, Rinaldi B, Melillo RM, Liotti F, Nappi A, Bianco R, Berrino L, Ciuffreda LP, Ciardiello D, Iaffaioli V, Botti G, Ferraiolo F and Ciardiello F: AXL is an oncotarget in human colorectal cancer. Oncotarget 6(27): 2328123296, 2015.

28 Levin PA, Brekken RA, Byers LA, Heymach JV and Gerber DE: AXL receptor axis: a new therapeutic target in lung cancer. $J$ Thorac Oncol 11(8): 1357-1362, 2016.

29 Han J, Tian R, Yong B, Luo C, Tan P, Shen J and Peng T: GAS6/AXL mediates tumor cell apoptosis, migration and invasion and predicts the clinical outcome of osteosarcoma patients. Biochem Biophys Res Commun 435(3): 493-500, 2013.

30 Salian-Mehta S, Xu M and Wierman ME: AXL and MET crosstalk to promote gonadotropin-releasing hormone $(\mathrm{GnRH})$ neuronal cell migration and survival. Mol Cell Endocrinol 374(1-2): 92-100, 2013 
31 Jiang $\mathrm{C}$, Zhou $\mathrm{L}$, Wang $\mathrm{H}$, Zhang $\mathrm{Q}$ and $\mathrm{Xu} \mathrm{Y}$ : AXL Is a potential cancer prognostic marker for the migration and invasion of nasopharyngeal carcinoma. Adv Clin Exp Med 25(3): 531-537, 2016.

32 Ultee A, Kets EP and Smid EJ: Mechanisms of action of carvacrol on the food-borne pathogen Bacillus cereus. Appl Environ Microbiol 65(10): 4606-4610, 1999.

33 Luo Y, Wu JY, Lu MH, Shi Z, Na N and Di JM: Carvacrol alleviates prostate cancer cell proliferation, migration and invasion through regulation of PI3K/AKT and MAPK signaling pathways. Oxid Med Cell Longev 2016: 1469693, 2016.

34 Chen WL, Barszczyk A, Turlova E, Deurloo M, Liu B, Yang BB, Rutka JT, Feng ZP and Sun HS: Inhibition of TRPM7 by carvacrol suppresses glioblastoma cell proliferation, migration and invasion. Oncotarget 6(18): 16321-16340, 2015.

35 Arunasree KM: Anti-proliferative effects of carvacrol on a human metastatic breast cancer cell line, MDA-MB 231. Phytomedicine 17(8-9): 581-588, 2010.

36 Fan K, Li X, Cao Y, Qi H, Li L, Zhang Q and Sun H: Carvacrol inhibits proliferation and induces apoptosis in human colon cancer cells. Anticancer Drugs 26(8): 813-823, 2015.

37 Maryam K, Shakeri S and Kiani K: Preparation and in vitro investigation of antigastric cancer activities of carvacrol-loaded human serum albumin nanoparticles. IET Nanobiotechnol 9(5): 294-299, 2015.
38 Yin QH, Yan FX, Zu XY, Wu YH, Wu XP, Liao MC, Deng SW, Yin LL and Zhuang YZ: Anti-proliferative and pro-apoptotic effect of carvacrol on human hepatocellular carcinoma cell line HepG-2. Cytotechnology 64(1): 43-51, 2012.

39 Koparal AT and Zeytinoglu M: Effects of carvacrol on a human non-small cell lung cancer (NSCLC) cell line, A549. Cytotechnology 43(1-3): 149-154, 2003.

40 Liang WZ, Chou CT, Lu T, Chi CC, Tseng LL, Pan CC, Lin KL, Kuo CC and Jan CR: The mechanism of carvacrol-evoked $\left[\mathrm{Ca}^{2+}\right]$ i rises and non-Ca ${ }^{2+}$-triggered cell death in $\mathrm{OC} 2$ human oral cancer cells. Toxicology 303: 152-161, 2013.

Received October 17, 2017

Revised November 2, 2017

Accepted November 8, 2017 